\title{
An Analysis of Risks of Electric Charge in Electric Network Enterprises under the Influences of the Financial Crisis and Causes for the Risks
}

\author{
Yimin Liu \\ School of Economics and Management, North China Electric Power University \\ Beijing 102206, China \\ Kun Zhou \\ School of Business Administration, North China Electric Power University \\ Baoding 071003, China \\ Haiyang Hou \\ School of Business Administration, North China Electric Power University \\ Baoding 071003, China \\ Jinpeng Liu (Corresponding author) \\ School of Economics and Management, North China Electric Power University \\ Beijing 102206, China \\ E-mail: hbdlljp@163.com
}

Received: May 13, 2011 Accepted: May 30, 2011 doi:10.5539/ass.v7n9p109

\begin{abstract}
The financial crisis has exerted influences of different degrees within a global scope, and, in the meanwhile, has brought about definite risks to the electric charge management in electric network enterprises. This paper makes a comprehensive analysis of prominent risks and characteristic changes in electric charge management in electric network enterprises under influences of the financial crisis, and studies the sources and major causes for the risks of electric charge by taking Hunan Electric Power Company as the case study, which has great reference significance for electric network enterprises to further strengthen the electric charge management work and enhance the comprehensive risk management level.
\end{abstract}

Keywords: Financial crisis, Electric network enterprises, Risks of electric charge

\section{Introduction}

Ever since late September 2008, the survival environment of enterprises in China has been persistently deteriorating as a result of the influences of the global financial crisis, the decelerated domestic economic growth, market sluggishness, rise in the price of raw materials, adjustment of the industrial structure, adjustment of the electric price and the tax policy of the nation, etc. The operation environment has also been deteriorating in the following industries which occupy a leading position in the electricity sales of the electric network enterprises: steel, building material, chemical engineering, automobile, electrolytic aluminium, real estate and textile, etc.. Consequently, quite a large number of enterprises are compelled to stop production and even shut down, as a result of which the electricity sales obviously decline and the rate of increase in the electricity sales of electric network enterprises obviously falls after rise. Furthermore, the products of the enterprises are kept long in stock, which results in slowed withdrawal of capital, serious shortage of working capital, broken upstream and downstream industrial chains that give rise to new defaulting chains, more complicated and difficult electric charge recovery environment, continuously increasing risk in the newly defaulted electric charge and more and 
more difficult recovery of formerly defaulted electric charge which is more serious in defaulting of enterprises with high consumption of energy. In the recent two years, the global economic growth has been still decelerated and contradictions and problems in the domestic economic running become more obvious. As a result, the operation situation in electric network enterprises becomes more difficult and the situation of recovering the electric charge becomes more austere.

\section{Prominent risks faced up by electric charge management under the influences of the financial crisis}

\subsection{The financial crisis leading to declining capacity of electricity utilization of clients}

Affected by the financial crisis, the electricity utilization amount in China fell back swiftly. In 2008, the electricity utilization amount in the whole country gradually slowed down in its speed of increase, and the total electricity utilization amount all over the country in the whole year was 3426.8 billion kilowatt-hours, with an increase of $5.23 \%$ compared with the same period of the previous year and falling $9.57 \%$ compared with the previous year. That had been the lowest speed of increase ever since the year 2000. Not only the total electricity utilization amount in the fourth quarter of this year was the lowest, but also a negative growth of over $7 \%$ appeared during that period. The amount of electricity utilization by industries accounted for a large proportion of the total electricity utilization amount in the whole society. The financial crisis led to declined demands by the market on industrial products, and production of enterprises gradually reduced and their electricity utilization also declined, which were the major factors that led to reduced electricity utilization amount and declining electricity utilization capacity of the whole society. In 2008, the total electricity utilization amount in the secondary industry reached 2586.3 billion kilowatt-hours, only increasing $3.83 \%$. The rate of increase in electricity utilization amount in the secondary industry, for the first time, was lower than the rate of increase in electricity utilization amount of the whole society.

Since the economic structure in Hunan Province is centered with industries of high consumption of energy, influences of the financial crisis upon them are more direct, and the range of declining in electricity utilization amount was quite severe. According to statistics, the electricity utilization amount of the whole society in Hunan Province in 2008 was 64.993 billion kilowatt-hours, which increased by $3.51 \%$ compared with the same period of the former year and fell by 13.66 percentages than the previous year, with an increase rate of merely $1 / 5$ compared with the year 2007. Amount of electricity utilization by large industries was 32.209 billion kilowatt-hours, which accounted for $49.56 \%$ of the total amount of electricity utilization by the whole society, but which only increased by $0.74 \%$ compared with the previous year, 2.77 percentage points lower than the speed of increase in amount of electricity utilization in the whole society. Furthermore, all large industries had a negative growth of electricity utilization amount in each month of the fourth quarter. The direct outcome brought about by the economic recession will necessarily be the shrunk entire consumption market, which, in turn, is especially prominent in the industries of catering, entertainment, commodity retail and wholesale, etc. The shrunk consumption market leads to recued amount of electricity utilization and declining electricity utilization capacity of these large industries. Reduction of the amount of electricity utilization directly affects sales income and realization of the profit of the enterprises and their capacity of profit-making is also seriously affected.

\subsection{The financial crisis leading to declining repayment capacity and repayment will of clients}

Affected by the financial crisis, quite a large number of enterprises get impacted in their economic benefits, as a result of which they go bankrupt and are shut down, losing the capacity of repayment. Bankruptcy and shutting down of these enterprises give rise to the double losses both in electric charge and liquidated damages of the electric network companies. Enterprises of electricity utilizers which are at a state of shut-down and semi-shutdown are also on an increase to a large extent. The operation effectiveness of these enterprises is in a negative condition, as a result of which their capital chain is broken, unable to make both ends meet, their capacity of repayment declines, they can't pay for their electric charge and arrearage happens in their electric bill. It is exactly as a result of emergence of the financial crisis that the economic competence of the clients is greatly frustrated. Thus, their will of repayment obviously declines and they try every means to take each excuse to default the electric bill.

Through the above analysis, it can be found that, the enterprises are faced up with the double pressure of reduced sales income and increased arrearage in the electric bill in the environment of the financial crisis, which leads to reduced profit and unsmooth cash flow. Hence, if these enterprises are unable to control and manage risks in electric charge in an appropriate way, this might affect the repayment capacity of the enterprises, their operation capacity and profit-making capacity in the future. 


\section{Changes of features of risks in electric charge under the influences of the financial crisis}

\subsection{Changes in the structure of the clients who default electric charge}

We make an analysis by taking as the case study data of recovery of electric bill in Hunan Electric Power Company in the recent five years, and the entire electric bill risk structure has taken great changes as a result of the financial crisis. Arrearage of enterprise clients in the year 2005 and the year 2006 was zero, and almost all clients who defaulted the electric charge were residents, so the risk in electric bill mainly came from arrearage of utilization of electricity for living of urban and rural residents. There was no arrearage in the year 2007. However, the total arrearage of the entire industry in Hunan Electric Power Company in 2008 amounted to 33.229 million Renminbi Yuan, including 27.5775 million Renminbi Yuan in arrearage of industrial electricity utilization and 5.6515 million Renminbi Yuan in arrearage of living electricity utilization of urban and rural residents, with the major electricity charge risk coming from arrearage of industrial electricity utilization. This was mainly because the financial crisis caused lots of enterprises to be compelled to stop production and even shut down. As a result, the working capital was in serious shortage and these enterprises were unable to pay for their electric bill. Thus, arrearage of industrial electricity utilization increased rapidly. Arrearage of industrial electricity utilization was mainly owing to arrearage of the secondary industrial electricity utilization, and second was the arrearage of electricity utilization in the tertiary industry. The financial crisis had relatively small influences upon recovery of electric bill of living electricity utilization of urban and rural residents. Arrearage of living electricity utilization of urban and rural residents was mainly due to electricity utilization of urban and town residents, and second was electricity utilization of rural residents.

\subsection{Changes in the environment of credit in electric charge collection}

In realistic life, quite a lot of enterprises and residents have no good faith and even borrow a variety of excuses and means to default their electric bill. Some enterprises take advantages of leakage in policies and legal regulations to default their electric bill with malevolence and eve3n directly steal electricity to avoid paying for their electric bill. According to data in 2004, it was discovered through statistics by the electric power department that, the amount of electricity that was stolen each year in the whole province of Hunan exceeded 0.2 billion kilowatt-hours, which amounted to the amount of electricity utilization of a medium-sized county within one year. Quite a lot of enterprises and residents have misunderstandings in their awareness, and they are unaware that electricity is a sort of commodity. The idea of "electricity utilization first and then payment of the electric bill" has been firmly rooted in their mind, and they have no consciousness to pay for the electric bill in time, reluctant to make deposit and to pay for the electric bill actively. After the outbreak of the financial crisis, the situation of defaulting in electricity bill has become more and more serious and a large number of enterprises and residents resort to the wind of the financial crisis to default their electric bill more willfully with the excuses of difficult operation, shortage in capital and hard living, etc. Loss of credit among enterprises and residents bring about huge losses and highs risks in recovery of electric bill to the electric network companies.

\section{Sources of risks in recovery of electric bill under influences of the financial crisis}

\subsection{Risks caused by improper operation of the enterprises}

\subsubsection{Most defaulting enterprises are large-scale state-owned enterprises that are improperly operated}

With gradual establishment of improvement of the market economic system in the 90s in the Twentieth Century, loss of the governmental protection made state-owned enterprises improperly operated. With adjustment of the industrial structure and increasingly fierce market economic competition, there will necessarily be a lot of enterprises each year which make a loss or shut down to reform their system. With implementation of such policies of "shutdown, stop of production, mergering, transfer and moving", there are some enterprises that are shut down, stop production and go bankrupt. Especially ever since the financial crisis that broke out in 2008, as a result of shrunk market demand, reduced sales of products and declining capacity of profit-making, quite a large quantity of enterprises have gone bankrupt. What's more, arrearage of enterprises that go bankrupt and reform their system are more a troublesome issue in recovery of electric bill by the electric network companies. Usually, these enterprises put electric charge at the end of all items to be paid, which results in arrearage of electric charge.

\subsubsection{Most defaulting enterprises are those with high consumption of energy}

Let's take Hunan Province as the case study. Hunan is a base for production of energy and raw materials, and annual production of steel, cement and coal requires huge electricity utilization amount, and, furthermore, cement, steel and smelting all belong to industries with high consumption of energy. According to an analysis, production of one ton of cement consumes 40 kilowatt hours of electricity and smelting of one ton of steel needs 
more than 600 kilowatt hours of electricity. All these enterprises have enormous consumption of electricity, and so long as they don't pay for the electric bill in time for a short period of time, their electric charge will become much higher just like a rolling snowball. After outbreak of the financial crisis, this phenomenon has been existing all the time and enterprises with high consumption of energy is a great hidden danger to recovery of electric bill by the electric network companies.

\subsection{Risks caused by loss of credit of the enterprises}

Under the influences of the financial crisis, as a result of deteriorated operation condition, some enterprises are in shortage of their capital chain and the mobility of their capital is not sufficient. Moreover, quite a lot of defaulting enterprises are capital intensive enterprises, so they are greatly dependent on capital. Besides, lots of electricity utilization clients don't observe contracts and keep their promises, especially those clients who are difficult in operation and who are shortage of capital. They have no consciousness of paying for their electric bill in time, and they always try every means to take a variety of excuses to default their electric bill and thus they occupy the capital that is supposed to belong to the electric network companies to seek for their own interests. Considering the subjects of defaulting electric bill, they are usually some enterprises with high consumption of energy, industries with high risks and large industrial clients. They not only utilize huge amount of electricity, but are also supposed to pay for huge electricity charge. There are also some resident clients who have weak consciousness in utilizing electricity pursuant to the law and paying for the electric bill pursuant to the law, and they often have a fluke mind, mistakenly believing that electric power belongs to the country and they may default so long as the condition requires.

\subsection{Risks caused by intervention of a third party}

Out of consideration of local protection and other factors, some local governmental departments often make interventions in the case that electric network companies decide to ration electric power in order to hasten defaulting clients to pay for their electric bill. The reason is that electric power industry has great influences upon economic development and living condition of the public group. Thus, once the power rationing is put into practice, it will affect a series of problems, such as, production of enterprises, employment, normal income of the public, social stability and confidence in recovery of the financial condition, etc. In order to resolve disputes and alleviate contradictions, the governmental departments have no other choice but to show up to make administrative mediation, such as, ordering the electric network companies to recover power supply, etc. Therefore, the attribute of electric power commodities is often restrained to a certain extent, which may give rise to arrearage of electric charge.

\section{Analysis of causes for risks in recovery of electric bill}

\subsection{The electric network enterprises assume public service functions}

Electric power belongs to public commodity and electric network enterprises belong to social public utilities. Arrearage of clients to electric network companies seriously affects the benefits of electric network companies. Since the electric network companies assume social public service functions, their behavioral targets have the characteristics of diversification. In the market economic condition, electric network companies also have to practically satisfy demands of national economic development and improvement of people's life quality on electric power in addition to pursuing economic benefits and ensuring maintenance and appreciation of values of the state-owned property as state-owned enterprises. In addition, they have to offer high-quality, convenient and economical service for power generation enterprises and electric power users and have to regard secure supply of electricity and first-rate service as one of the primary targets of the enterprises all the time. However, with outbreak of the financial crisis, heavy losses are inflicted on the national economy, and the life quality of the people is seriously affected. As state-owned enterprises, electric network companies assume the public service functions, so even if they can't make both ends meet themselves and even if their clients default their electric bill, they also have to have the perseverance to offer sufficient and first-rate electric power products for their clients for stability and development of the nation and for vital interests of the people. Therefore, compared with general competitive enterprises, electric network companies more assume the task of realizing the public target of the nation.

\subsection{The payment model of electricity utilization first and then electricity bill}

Electricity is a sort of particular commodity and trade of electricity can only be manifested as the mode of real time measurement and settlement after the event. Management of charging the electric bill by former electric network companies was "electricity utilization first and then payment of the electric bill". From the perspective of marketing, this mode of "electricity utilization first and then payment of the electric bill" is, as a matter of fact, 
a model of sales on credit, which is also termed as credit selling model. The mode of payment for electric bill requires both of the two parties of electricity supply and electricity utilization negotiate to be consistent and we can't take coercive measures to require all clients to make prepayment for their electric bill. Especially for those industries and commercial clients who have a large amount of electricity utilization, if they make prepayment for their electric bill, it means they keep long in stock their working capital. Reduction on working capital would give rise to definite capital pressure upon the operation activities of these enterprises. Nevertheless, essentially, it means has nothing different to let electric power departments pay for the costs of generating and supplying of electricity for their clients. There are even some clients who are unable to pay for their electric bill by due date due to certain reasons, arrearage happens and even bad loan and dead loan, which will lead to great losses to the electric network companies. Especially under the influences of the financial crisis which broke out in the year 2008, some enterprises decreased in their capacity of profit-making and they even made a loss and went bankrupt. Consequently, some enterprises had no capacity of paying for their electric bill after they had utilized the electricity, and even some defaulting clients could no longer be found, so essentially there was no way to claim for the electric charge.

\subsection{The economic environment is difficult to predict}

Influences of the financial crisis are manifested in detail as follows: aggravated imbalance of the global economy, decelerated speed of increase of the economic development, more fierce international and domestic competition, aggravated trade protectionism, more trade frictions, continuously deteriorated external environment, great pressure in growth of export, slowdown tendency of consumption growth, medium phase of adjustment in the real estate market, obviously declining capacity of profit making and obviously weakened motive of growth in economic endogeneity, etc. All these continuously changing factors cause the electric charge to be faced up with more uncertainty and the risks in recovery of electric bill rise.

\subsection{Disadvantages in management work of risks in electric charge in electric network enterprises}

A comparison of practical experiences in risk management in domestic and foreign enterprises, we can find out the following several disadvantages in the risk management of electric charge by electric network enterprises. Firstly, establishment of the system of risk management of electric charge calls for further united planning and deployment. Yet, great discrepancies exist between foundations of work in different power supply companies, which requires to further unify risk standard and risk management flow and to further strengthen overall planning of establishment of the system. Secondly, the overall process of risk management of electric charge based on overall risk management is urgently required to be established. Although power supply companies have certain explanations and introductions to some important aspects in the overall process of risk management of electric charge, an overall process of risk management of electric charge based on the overall risk management still needs to be established, since this process is not only the process of risk management of the electric charge of the companies, but also the foundation for all departments of the companies to make an assessment on the risk management of the electric charge. Thirdly, the system of report on risk management of electric charge needs to be continuously improved and establishment of information system to adapt to the risk management of electric charge is also extremely necessary. In the meanwhile, dynamic monitoring and assessment of the risk management of electric charge of the companies and continuously improved mechanism measures still need to be make sound so as to guarantee effective implementation and everlasting improvement of the risk management of electric charge and guarantee the system of risk management of electric charge will continue to play its pushing role in realization of the strategic goal. Finally, establishment of corporate culture to comply with the establishment of risk management system of electric charge also is urgently to be strengthened. In the long term risk management work of electric charge, quite a large quantity of employees have already had better risk consciousness, but there are still some employees with weak consciousness of risk and have no enough knowledge in the importance and necessity of risk management of electric charge. Consequently, the phenomena often occur which cause incidents of violating the law as a result of not observing relevant rules and regulations,

\section{Conclusion}

Based on an analysis of the macro environment of overall influences of the financial crisis upon enterprises, this paper has meticulously studied relevant issues of risks in electric charge in electric network enterprises. On one hand, the authors described prominent risks and feature changes in electric network enterprises in the realistic environment. On the other hand, the authors made an in-depth exploration into sources of and causes for the risks, which would not only push forward enrichment of the theory of risk management, but would also offer perfect analysis platform for enterprises to resolve realistic issues. 


\section{References}

Huang, Baozhu. (2006). On the Tariff Recovery Risk and Countermeasures. Rural Electrician, (03).

Liu, Huibo. (2007). Pre-control management of retrieving electricity bill risk. Distribution \& Utilization, (02).

Tang, Haiyan. (2009). Countermeasures to Implementation of Recovery of Electric Bill. Popular Utilization of Electricity, (03).

Wang, Jing. (2009). Brief Discussion on Improvement of the Recovery of Electric Bill by Power Supply Companies. China Electric Power Education, (17).

Xie, Wanchun. (2009). Graded Early Warning of Electric Bill. China Power Enterprise Management, (05).

Zhang, Yuanzhen. (2007). Management of Graded and Classified Early Warning of Electric Bill. China Power Enterprise Management, (05). 